Boston University School of Law

Scholarly Commons at Boston University School of Law

Faculty Scholarship

1997

Patients' Rights in Managed Care - Exit, Voice, and Choice

George J. Annas

Follow this and additional works at: https://scholarship.law.bu.edu/faculty_scholarship

Part of the Health Law and Policy Commons 
Legal Issues in Medicine

\section{Patients' Rights in Managed Care - Exit, Voice, ANd Choice}

\author{
George J. AnNAS, J.D., M.P.H.
}

$\mathrm{T}$ HE ability of consumers to complain effectively about services and products is a key ingredient of the market. In Exit, Voice, and Loyalty, ${ }_{1}^{1}$ economist Albert O. Hirschman argues that the ability to take one's business elsewhere may not be enough to empower consumers in markets where all providers act similarly. Instead of simply going elsewhere, consumers need to have an effective way to voice their complaints, in order to give providers an incentive to be more responsive to consumers' interests. ${ }^{1}$ Marc Rodwin has suggested that the Hirschman analysis may be particularly relevant to members of managed-care organizations and "individuals with on-going relations with providers such as nursing homes." 2

Providing patients, who depend on their physicians for expert advice, with an effective voice is a long-standing problem that has been highlighted, but not caused, by managed care. ${ }^{2}$ The backlash against managed care, however, provides an opportunity to develop meaningful options for patients. ${ }^{3}$ In this regard, the questions of dispute resolution, grievance mechanisms, and appeals procedures have recently taken on urgency in the courtroom, as well as in proposals for legislative reform at the state and federal levels. Here I examine the decisions of U.S. District Court Judge Alfredo C. Marquez in Grijalva v. Shalala, ${ }^{4}$ a class-action suit on behalf of the Medicare members of a health maintenance organization (HMO), which sought to compel the Department of Health and Human Services (HHS) to adopt more user-friendly rules for appeals. The classaction suit was brought by the Center for Medicare Advocacy and other public-interest groups on behalf of patients like Gregoria Grijalva, an elderly amputee with an indwelling catheter, who had been told by the HMO that she was not eligible to receive home health care.

\section{MEDICARE HMOs}

All health insurers have problems with dispute resolution. Managed-care organizations are nonetheless under special scrutiny, because denial of treatment is more common, physicians may be restricted in their role as advocates for their patients, and patients may have little opportunity to leave the plan ("exit"). Federal law requires that HMOs enrolling
Medicare patients provide them with the same range of services provided to Medicare patients not enrolled in HMOs. ${ }^{5,6}$ The law also requires that HMOs provide "meaningful procedures for hearing and resolving grievances" between the HMO and its Medicare members. ${ }^{5}$ Dissatisfied enrollees have a right to a hearing before an administrative-law judge, if the dispute involves $\$ 100$ or more, or a judicial review, if the amount exceeds $\$ 1,000 .{ }^{6}$ HMOs must have procedures for appealing the denial of payment for emergency treatment, the denial of payment for services rendered by a non-HMO provider, and the refusal to provide services. ${ }^{6}$ The essence of the complaint in Grijalva was that HMOs were not following these appeals requirements and that HHS was not enforcing them, thus violating both the statutory and the constitutional due-process rights of Medicare recipients. ${ }^{4}$

HHS argued that it was doing all it was statutorily required to do by urging its private contractors to adopt continuous-quality-improvement procedures and that the HMOs involved were "merely private providers who contract with the government to provide medical care to Medicare beneficiaries." ${ }^{4}$ HHS further argued that the government was not responsible for wrongful acts by private HMO contractors, so the Constitution did not apply. This argument was based almost exclusively on a 1982 Supreme Court case, Blum v. Yaretsky, ${ }^{7}$ in which the Court decided that a nursing home's decision to transfer its Medicare and Medicaid patients to another facility was a private act. The transfer was necessitated by the government's decision to decertify the nursing home for Medicaid and Medicare patients. The Court concluded that since the transfer itself involved no action on the part of the government, the residents had no right, under the due-process clause of the Constitution, to a hearing before the transfer. ${ }^{7}$

Judge Marquez, however, found that Blum was not determinative in the Grijalva case, because HHS "had delegated the entire responsibility for its mandated . . . health care duties" to the HMOs. ${ }^{4}$ He cited a case involving certified home-health-care agencies, which are private entities, in which the court concluded, "It is patently unreasonable to presume that Congress would permit a state to disclaim federal responsibilities by contracting away its obligations to a private entity. ${ }^{4,8}$ Criteria that courts have used to find private health care entities subject to constitutional due-process standards include government payment for services, government regulation of HMO activities as they apply to Medicare recipients, HHS regulations and directives to HMOs, the creation by HHS of a legal framework governing HMO activities, and the right of Medicare beneficiaries in HMOs to appeal directly to the secretary of HHS in the case of a denial of services. ${ }^{4,8}$ Applying these factors, Judge Marquez found sufficient evi- 
dence of government action to invoke the constitutional rights of due process. The next step was for the judge to determine the due-process rights of the plaintiffs in Grijalva - that is, the dispute-resolution process required by the Constitution.

\section{MANAGED-CARE DISPUTES}

There are major distinctions between indemnity, or fee-for-service, insurance plans and risk-bearing managed-care plans when it comes to disputes over benefit determinations. With fee-for-service insurance, the medical services have typically already been rendered, and the only remaining issue is payment. In addition, the physician can usually be expected to act as the patient's advocate with regard to retrospective denial of payment. ${ }^{4}$ In managed-care plans, however, disputes often occur before the medical services have been rendered, and the physician often acts as the gatekeeper who decides that a specific medical service sought by the patient is not needed. Physicians in managed-care plans may also have a financial incentive not to advocate for the patient, although there is no uniform way in which physicians are paid. ${ }^{4}$

Most important, taking one's business elsewhere is an almost cost-free option for patients with indemnity insurance, who can usually simply go to another physician for the care they want and have it paid for. But this is not a realistic option for most members of managed-care organizations, because employers may limit their employees' choice of plans, employees may not be able to afford a more expensive plan or to pay out of pocket, and the opportunity to change plans is usually limited to one brief period a year, which is often not the time when medical care is sought. These generic problems, however, primarily involve people under the age of 65 years. In Medicare, exit is freely available, and in a recent twoyear period, one out of three Medicare patients in managed care returned to indemnity insurance. ${ }^{5}$ So the ability to voice complaints is even more important for non-Medicare patients, who may not realistically have the choice of exiting the plan, than for Medicare patients in managed-care organizations.

HHS argued that in 1993 and 1994 the rates of appeals for denials of service by fee-for-service insurers were 27 and 31 times as high, respectively, as those for denials by HMOs. ${ }^{4}$ HHS contended that the much lower rates of appeals for HMOs were evidence of the good job they were doing. The judge, however, concluded that a more likely explanation for this wide discrepancy was the failure of HMOs to provide a meaningful appeals process. ${ }^{4}$ The judge noted, for example, that a review of $\mathbf{5 7 0}$ denial notices to HMO members disclosed three problems. First, 52 percent of the notices were illegible, primarily because most were printed in type that was smaller than 12 points, the recognized minimal print size for readability by elderly persons. Second, 74 percent of the notices provided vague or ambiguous reasons for denial of services. Third, only 41 percent of the notices contained an explanation of personal liability resulting from care incurred subsequent to the denial. ${ }^{4}$

Judge Marquez also found that the notices tended to "hide the ball" by obscuring the eligibility requirements, thus making it very difficult for a claimant to "fathom what additional evidence to present to rebut the denial." $4 \mathrm{He}$ was also concerned about the general lack of an opportunity to present one's appeal in a face-to-face setting such as an informal hearing and noted, "Due process requires a meaningful opportunity to present one's case at a meaningful time." $4 \mathrm{He}$ further observed that denial of treatment can result in "unnecessary pain and suffering or death," ${ }^{4}$ and thus the ability to appeal an adverse decision quickly is essential to due process in these circumstances.

Exactly what process is due a person under the Constitution depends on a balancing test that includes an examination of "the private interest at stake; the risk of an erroneous deprivation; the probable value of additional procedural safeguards; and the fiscal and administrative burdens" that the additional safeguards would require. ${ }^{4}$ The Supreme Court has ruled, for example, that an evidentiary hearing is required before welfare benefits are terminated ${ }^{9}$ but not when disability benefits are denied..$^{10}$ In the welfare case, which Judge Marquez found to be most like the denial of medical treatment, the court had noted that "termination of aid pending resolution of a controversy over eligibility may deprive an eligible recipient of the very means by which to live while he waits." Similarly, of course, denial of a needed treatment could lead to death or severe suffering. Welfare recipients have a due-process right to the following when benefits are to be terminated: timely and adequate notice of the reasons for termination; an effective opportunity to appeal the termination by confronting adverse witnesses and presenting evidence orally; legal counsel, if desired; an impartial decision maker; a decision based on law and evidence presented at the hearing; and a statement of reasons for the decision. ${ }^{9}$

Applying these constitutional due-process guidelines, Judge Marquez concluded that HHS had violated federal law by continuing to contract with an HMO that failed to meet the following constitutional requirements with respect to notice and hearings:

Notice: 1. Shall always be given for any and all denials of service;

2. Shall be timely;

3. Shall be readable: at least 12-point type;

4. Shall state the reasons for denial clearly and in such terms as to enable the enrollee to argue his or her case;

5. Shall inform the enrollee of all appeal rights, 
including PRO [peer-review-organization] review;

6. Shall inform the enrollee of the right to a hearing on reconsideration and that additional evidence may be presented, in person, and shall explain the procedure for securing an informal hearing; and

7. Shall provide instruction on how to obtain supporting evidence, including medical records and supporting affidavits from the attending physician. The HMO must abolish any policy or procedure which would impede such advocacy. 4

Hearing: 1. Shall be informal, in-person communication with the decisionmaker;

2. Shall be available upon request for all service denials; and

3. Shall be timely according to the seriousness of the medical condition implicated by the denied service: Immediate hearing shall be available for acute care service denials, specifically where delivery of the service is prevented by the denial. . . . All other hearings can be within the normal course of the HMO's 60-day time frame for reconsideration. ${ }^{4}$

\section{AFTERMATH OF THE GRIJALVA DECISION}

The Grijalva criteria apply only to the approximately 5 million Medicare patients in HMOs. But problems with dispute resolution must be addressed throughout the health care industry. Fair procedures for the resolution of disputes are critical, because decisions that are not subject to review by impartial decision makers are themselves unlikely to be made fairly when there are financial incentives not to provide treatment. Of course, persons "often lack the resources, the stamina, or the inclination" to use grievance processes, even when such procedures are available ${ }^{2}$ and many people fear that a complaint could result in retaliation, especially "in managed care because consumers are locked into a formidable organization."2 Effective dispute-resolution mechanisms must be easier to use and less threatening than existing mechanisms. Facilitating appeals ("voice" and "choice") in the form of fair dispute-resolution mechanisms should help improve both access to services and the quality of care.

In late 1996, the American Association of Health Plans, which represents more than 1000 managedcare plans, pledged to streamline appeals processes and make them more "patient-friendly." 11 The association said that its member plans "recognize that accessible, fair, and timely grievance and appeals procedures must be in place and understood by both enrollees and all providers and health plan personnel."11 The group repeated its pledge in early $1997 .{ }^{12}$

HHS announced that it would adopt new regulations to bring it into compliance with the decision. ${ }^{13}$ Nonetheless, Judge Marquez issued an additional ruling in March 1997, ${ }^{14}$ in which he ordered Medi- care HMOs to provide written notice of a benefit denial "no more than five working days after written or oral request for a service or referral" or "at least one working day before reduction or termination of a course of treatment." 14 He also ordered that the notice be "clear, readable" and "in at least 12-point type" and that it include "an explanation in lay language of the coverage rule" on which the decision is based, an explanation of appeals available, a description of additional evidence that would support the enrollee's position and how it could be submitted, and procedures for securing an informal hearing before the decision maker for reconsideration. ${ }^{14} \mathrm{HHS}$ was required to provide enrollees with an expedited reconsideration within 3 working days, including inperson communication with the decision maker in cases in which "services are urgently needed," with the review itself completed within an additional 10 working days. ${ }^{14}$ Urgency can be established on the basis of a physician's written explanation, and plan doctors shall "be free to give supporting documentation without fear of retaliation or reprisal from the HMO."14

On April 30, HHS published its final rules for an expedited review process for Medicare beneficiaries enrolled in HMOs, ${ }^{15}$ effective as of June 30, with compliance expected by August 28. ${ }^{15}$ In an apparent attempt to camouflage its courtroom defeat, the department barely mentions Judge Marquez's opinion. Instead, HHS says it was guided primarily by a model grievance act prepared by the National Association of Insurance Commissioners. The rules require an expedited review process for any denial of service that could "jeopardize the life or health of the enrollee or the enrollee's ability to regain maximum function." The expedited review process must include acceptance of an oral request for a review, prompt notice as to whether the review will be expedited, notification of the decision within 72 hours after the request, and acceptance of a physician's request for an expedited review, regardless of whether the physician is affiliated with the organization. Should the request be denied, the enrollee also has the right to a reconsideration of the decision, including an expedited reconsideration under essentially the same procedures and with the same time frame as the initial review. ${ }^{15}$ Perhaps the most noteworthy provisions of these new rules are the notification of the decision within 72 hours (HMO representatives argued for five working days) and the mandatory expedited review when requested by a physician.

Consumer groups have criticized the rules, noting especially that they give the health plan the discretion to determine whether the beneficiary should receive an expedited review (if not requested by a physician) and do not require in-person communication with the patient for initial reconsiderations. Within 
days of publishing its new rules, HHS announced it would appeal Judge Marquez's March order.

Legislation mandating specific dispute-resolution mechanisms and appeals processes is also pending before the Congress and in many state legislatures. The issue is complex, but Judge Marquez has provided a very useful set of guidelines on which to base legislation that applies to all patients in all insurance plans.

\section{FACILITATING CHOICE}

As Judge Marquez understood, the role of the physician in the resolution of disputes over medical care is central. HMO managers often declare at national conferences that the physician can no longer be an advocate for the patient. The exact meaning of this statement is unclear, but it seems to imply that the traditional doctor-patient relationship is no longer financially feasible. Decisions about what is best for the patient are made in the context of that relationship, through a process of informed consent in which all reasonable medical alternatives are discussed, with the physician acting as the patient's advocate to ensure that the patient obtains the agreedon treatment. Of course, one may well agree with HMO managers that just such a system, driven by fee-for-service plans, led to overutilization, unnecessary care, and financial ruin. The new model requires physicians to advocate for a group of patients (i.e., the members of the managed-care organization) and take the allocation of resources within the group into account in presenting medical alternatives to their patients. In such a model, patients may be left alone to advocate for themselves if they believe they need a medical treatment that is either not mentioned by the physician or not covered by the plan. As an insurer, the managed-care organization (like all insurers) has a financial incentive to encourage patients needing expensive medical treatments to leave the plan in order to obtain treatment and has no financial incentive to provide patients with an effective way to voice their objections to denial of treatment through a user-friendly process of dispute resolution.

All insurers have a financial incentive to discourage appeals, since the appeals process itself costs money, and a decision in favor of the patient will cost even more. Discouraging appeals may encourage patients to seek desired or needed care elsewhere and to pay for it themselves. Of course, patients must know about alternative treatments in order to seek them and must know about any financial incentives their physicians might have not to recommend alternative treatments or not to refer them to specialists or for diagnostic testing. Recognizing these problems, a circuit court of appeals has ruled in another case (Shea v. Eisenstein) that managed-care organizations must disclose physicians' financial incentives to pa- tients so that they can make informed decisions about whether or not to accept their physicians' advice. ${ }^{16}$ In this case, a primary care physician allegedly advised Patrick Shea, a 40-year-old man who was experiencing shortness of breath, muscle tingling, and dizziness and had an extensive family history of heart disease, that referral to a cardiologist was unnecessary because the patient was too young to have heart disease. ${ }^{16}$ The primary care physicians associated with the HMO, Medica Health Plans, operated by the Minneapolis-based Allied Health System, "were rewarded for not making covered referrals to specialists [by bonuses] and were docked a portion of their fees if they made too many." 16 The patient accepted the advice and soon thereafter died of a heart attack. His widow filed a wrongful-death action against the health plan, arguing that had her husband known about the way his physician was paid by the managed-care organization, he would have sought a second opinion from a heart specialist and paid for the consultation himself. ${ }^{16}$

This case and the HHS rules highlight the tension in the doctor-patient relationship created by capitation and the limits of even the best-designed dispute-resolution mechanism to address this tension. A user-friendly appeals mechanism that protects the physician from retaliation by the HMO can help the patient obtain a recommended treatment. But if the physician does not recommend a treatment or even suggest it as a reasonable option, the patient may not have sufficient knowledge to realize that a decision not to offer a treatment has been made. The possibility of appealing the decision may never enter the patient's mind. Of course, one could provide the equivalent of a warning label for all doctorpatient conversations, stating that the physician is being paid to minimize referrals and treatments, but this would simply serve to erode the patients' trust in their physicians. Although user-friendly appeals mechanisms are helpful, they cannot address the fundamental issue of trust in the doctor-patient relationship. And to the extent that managed-care organizations are undermining this trust by recasting the doctor-patient relationship, confronting the problem will require much more than simply providing more accessible dispute-resolution mechanisms.

A Wall Street Journal health columnist advises her affluent readers that if they are convinced they need a specialist and their plan balks, they should go to the specialist anyway, pay out of pocket, and "fight later about who [ultimately] pays." 17 But such responses put all the burden on patients and none on the managed-care organization and its physicians. This is unfair. Managed-care organizations and their physicians are certainly not incapable of error in making decisions about coverage. As Eleanor Kinney, an administrative-law expert, properly emphasizes, "It should never be forgotten that procedures 
are an important mechanism to confer power and adjust the balance of power among the parties to the process." 5 How should such a system be designed?

\section{DISPUTE-RESOLUTION MECHANISMS}

Mechanisms for resolving disputes about medical care should be quick, easy to use, and fair. In the case of prospectively denied services, patients should be able to obtain a second medical opinion within hours, and in the case of a denial of services that is based on contractual language, they should be able to appeal to an internal neutral decision maker within two days. It also seems reasonable for states to require that all health insurers in their jurisdictions have dispute-resolution procedures that not only meet the Grijalva requirements but go even further.

All patients, not just Medicare patients in HMOs, should have legally established grievance and appeals rights. Although some variation seems reasonable, the basic provisions, including those governing notification, review by a neutral decision maker, a timely response, and a written explanation of the reasons for the decision, should be uniform. In addition, the state should provide patients who have been turned down by the health plan and their physicians with a neutral and fair appeals process (separate from the judicial system), such as independent arbitration by a knowledgeable panel, which can quickly review and reverse or uphold an adverse decision. The hearing officers for these appeals could be members of the state health department. Decisions by independent arbitration panels should be binding on the health insurer, but because of the imbalance of power, patients should be able to appeal these decisions. In cases requiring treatment within days or weeks, the internal appeals process should take less than 48 hours, and the external appeals process no more than another 48 hours. In the case of an HMO's decision to discontinue ongoing treatment, whether inpatient or outpatient, treatment should be continued during the expedited appeals process.

Records of all internal and external appeals should be publicly available (although the names and identifying characteristics of patients can be withheld to protect their privacy) for the purpose of comparison and improvement in the quality of care. All costs of nonjudicial appeals should be borne by the insurer. Patients should always have the option to challenge decisions in court, but once a dispute is taken to court, both parties have already lost in terms of time, money, and efficiency in decision making. The closer to the bedside the dispute can be resolved, in terms of both time and distance, the better. ${ }^{18}$ No health care plan that is delivering high-quality medical care should have anything to fear from a speedy dispute-resolution process that treats patients fairly.

The primary problem with existing grievance mech- anisms is that they are slow and one-sided. A survey of 196 Kaiser Permanente arbitrations in northern California, completed between 1984 and 1988 and recently made public, found that the final resolution of disputes took an average of more than 28 months. ${ }^{19}$ If physicians cannot or will not act as their patients' advocates, some other party will have to assume this role for patients who wish to challenge denials of benefits quickly and effectively. It seems unlikely that a patient would be satisfied with an advocate hired by the health plan, and in any event, it is unlikely that such a person could act independently on the patient's behalf. If the system is to succeed in resolving disputes quickly, patients must believe that it is fair. Thus, advocates will have to be provided by an independent organization, such as the state consumer-protection agency or the state attorney general's office..$^{20}$ Of course, independent consumer groups could also make advocates available for patients. To be feasible, an advocacy program would require predictable funding. An increase in licensing fees paid by all entities doing business as health-insurance or claims-management companies seems a reasonable source of funding. Such funding should avoid preemption under the Employee Retirement Income Security Act, because it does not tax group health insurance benefits or premiums. ${ }^{21}$

Relying solely on the ability of patients to leave one health plan and move to another is not sufficient to ensure either the rights of patients in managed-care plans or improvement in the quality of care. Improving opportunities for enrollees to voice their objections can both enhance patients' rights and highlight areas of potential concern with respect to quality. In the past two years, most of the managed-care backlash has been played out in Congress and the state legislatures. Courts are slower to react but will intervene, especially in cases involving services to Medicare recipients and alleged violations of due process. Prevention is almost always preferable to cure, and the states and the federal government should act to ensure that all patients have access to dispute-resolution mechanisms that are quick, easy to use, and fair, as well as to advocates who can help them use these mechanisms. Supplementing the ability to exit with the ability to have an effective voice can foster choice and enhance patients' rights.

\section{REFERENCES}

1. Hirschman AO. Exit, voice, and loyalty: responses to decline in firms, organizations, and states. Cambridge, Mass.: Harvard University Press, 1970

2. Rodwin MA. Consumer protection and managed care: issues, reform proposals, and trade-offs. Houston Law Rev 1996;32:1319-81.

3. Bodenheimer T. The HMO backlash - righteous or reactionary? N Engl J Med 1996;335:1601-4.

4. Grijalva v. Shalala, 946 F.Supp. 747 (D.C. Arizona 1996).

5. Kinney ED. Procedural protections for patients in capitated health plans. Am J Law Med 1996;22:301-30. 
6. 42 US.C. $S \mathcal{S} 1395 \mathrm{~mm}$

7. Blum v. Yaretsky, 457 U.S. 991 (1982)

8. Catanzano v. Dowling, 60 F.3d 113 (2d Cir. 1995).

9. Goldberg v. Kelly, 397 U.S. 254 (1970)

10. Mathews v. Eldridge, 424 U.S. 319 (1976)

11. AAHP urges respect for appeals rights, additional safeguards in Medicare HMOs. BNA's Health Law Reporter. November 7, 1996:1631.

12. Gaynor P. Managed care standards may foil regulation. Pittsburgh

Post-Gazette. February 2, 1997:C-21

13. HCFA official says 'gag' clauses in risk contract HMOs may violate law. BNA's Managed Care Reporter. December 11, 1996:1159.

14. Grijalva v. Shalala, Civ 93-711, March 3, 1997, U.S. Dist. Ct. Arizona (Marquez, J.).

15. Department of Health and Human Services, Health Care Financing Administration. Medicare program: establishment of an expedited review process for Medicare beneficiaries enrolled in health maintenance organi- zations, competitive medical plans, and health care prepayment plans. Fed Regist 1997;62(83):23368-76.

16. Shea v. Eisenstein, 107 F.3d 625 (8 Cir. 1997).

17. Chase M. Knowing when you need the expertise of a specialist. Wall Street Journal. April 14, 1997:B1.

18. Annas GJ. The rights of patients. 2 nd ed. Carbondale: Southern Illinois University Press, 1989.

19. Hiltzik MA, Olmos DR. Kaiser justice system's fairness questioned. Los Angeles Times. August 30, 1995:Al.

20. Annas GJ, Healey J. The patient rights advocate: redefining the doctor-patient relationship in the hospital setting. Vanderbilt Law Rev 1974 $27: 243-69$.

21. Mariner WK. State regulation of managed care and the Employee Re tirement Income Security Act. N Engl J Med 1996;335:1986-90.

(C) 1997, Massachusetts Medical Society.

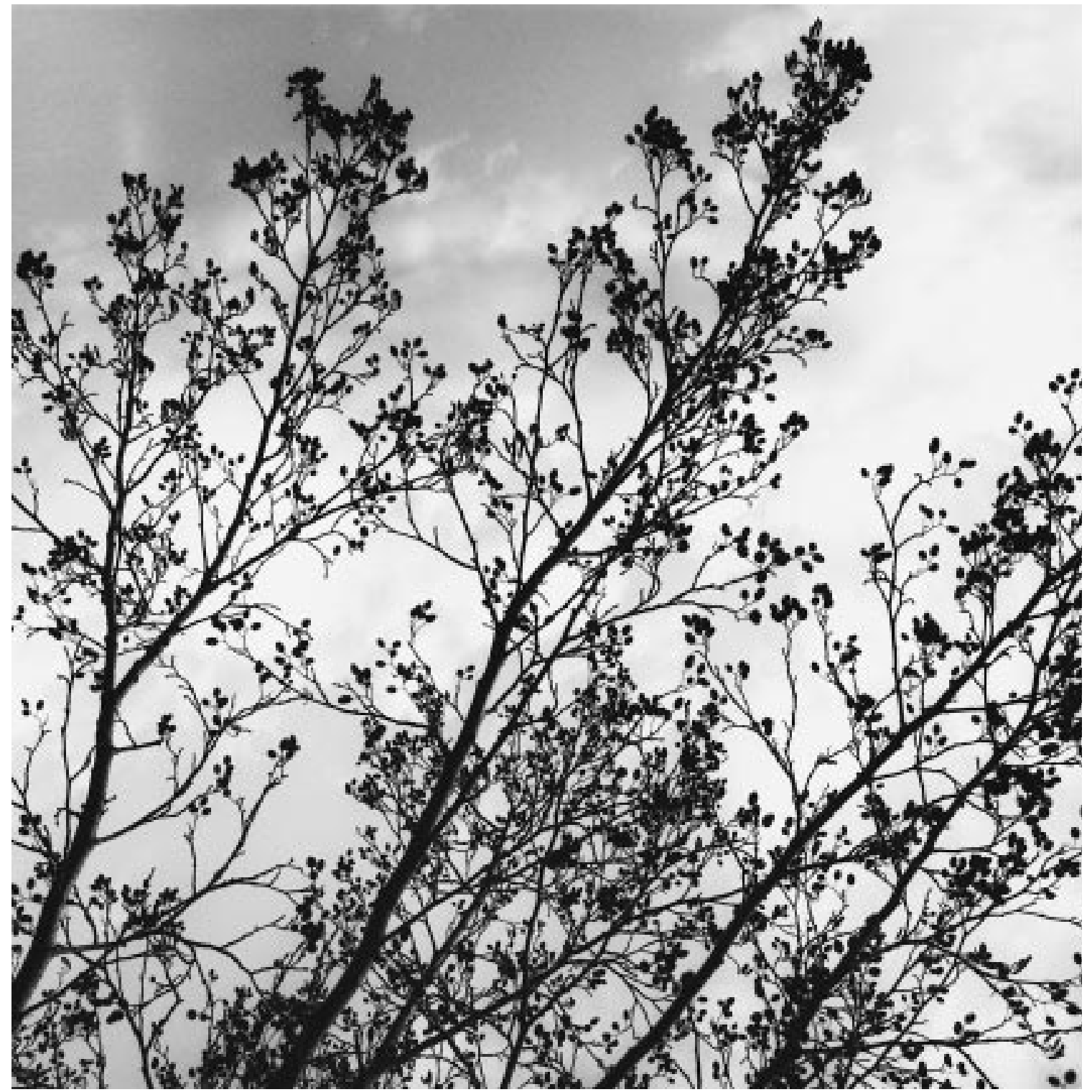

On the Banks of the Charles River

Robert S. SCHWARTZ, M.D. 